\title{
Etched in the Skin: Grief on a Living Canvas - Memorial Tattoos as Expressions of Grief
}

\author{
Bee Swann-Thomas, Susan Fleming and Emily Buckley
}

\begin{abstract}
This study was conducted to investigate how memorial tattoos impact upon the grieving process of individuals who wear them. Semi-structured interviews were conducted on a 1:1 basis with six diverse individuals and analysed using interpretative phenomenological analysis (IPA).
\end{abstract}

The findings suggest that memorial tattoos play a beneficial role within the grieving process and that they serve as a positive therapeutic tool. We found that memorial tattoos have five fundamental features: 1) Permanence, 2) A tool for managing grief, 3) Communicative tool, 4) Continuing bonds, 5) Transformation of self. As a result of our findings we recommend that a more flexible approach to the management of grief should be offered to bereaved individuals. We further propose that this study serves as a catalyst for the positive role memorial tattoos play in the grieving process and recommend further qualitative research to broaden our understandings of this area.

Keywords: grief; bereavement; memorial; tattoos; ritual

\section{Introduction}

Regardless of who we are, one thing that is certain is that we will, at some point, experience the death of a loved one. Their death causes us to simultaneously feel a plethora of emotions. Within Western cultures, the final rite of passage of a funeral or cremation marks the end of death (Robben, 2004), and the bereaved are then expected to move on and return to their normal duties (Leming \& Dickinson, 2020). Within psychology/counselling literature (e.g. Wakefield, 2013), it is considered "normal" to expect intense grief to last 6-12 months after the death of a loved one. In fact, in the stark reality of the loss of a loved one, for many, 
memorialisation does not end with the funeral and grief can continue for many years.

This study aims to illuminate and expand upon the lived experience of the grieving process and to specifically explore whether memorial tattoos are valuable tools in the grieving process. We also feel that it is important to critique previous grief models which hold that the bereaved should 'move on' in order to illustrate the uniqueness of grief and the importance of continuing bonds (Klass et al., 1996). Ideally this will allow for a more flexible approach to the management of grief within future practices.

\section{Grief}

One of the most difficult experiences we are likely to be faced with in life is the ubiquitous human experience of the death of a loved one (Boyraz et al., 2015). Grief consumes our whole being (Altmaier, 2011). Despite this, within Western Society as a whole, death and grieving are perceived as uncomfortable subjects and our society is illequipped to support those who are grieving (Morris, 2008). Over the past centuries the phenomenology of the grieving process has amassed a considerable body of literature (Bonanno \& Kaltman, 1999). In his seminal paper 'Mourning and Melancholia', Freud (1917) first postulated that the bereaved should relinquish their attachment to the deceased in order to end the mourning process. This was further supported by Lindemann (1944) who contended that the bereaved person should disconnect themselves from all thoughts and memories of the deceased in order for them to complete the process of 'grief work'. Lindemann believed that an individual's emotional connection to the deceased causes grief, and that it is only through relinquishing this connection that the process of 'grief work' can be completed and the bereaved can readjust to the world in which the deceased is missing. 
As a means of understanding and coping with dying Kübler-Ross (1969) developed an acceptance model which identified stages of grief ending in 'acceptance', which is often considered to be a 'moving on' implying that there is an end to the grieving process. A number of researchers since (e.g. Corr, 1993) have argued that grief is a complex process and that Kubler Ross' stages of grief are seen as being too linear, rigid and passive. Klass et al., (1996) argue that previous theories of 'letting go' of the deceased and 'moving on' do not relate to the reality of how individuals actually grieve. Despite this, these models of successful recovery from grief remain highly influential in clinical practice (Nolen-Hoeksema \& Larson, 1999).

Bowlby (1979) conversely advocated that a bereaved person can maintain an ongoing relationship with the deceased whilst also continuing with their life. This concept was further elucidated to in Worden's (1991) tasks of mourning. He proposed that the final task of grieving was to find an enduring connection with the deceased. Worden further acknowledged the uniqueness and complexities of grief, arguing that we should not expect every bereaved person to grieve in the same manner and Davis et al., (2000), suggest that if individuals are to create meaning after the loss they should be encouraged to follow their own individual processes. This suggests that people should be supported in finding an emotional place for the deceased in their lives rather than relinquishing their relationship (Worden, 1991). However, this is not how Western society tends to view grief.

\section{Grieving Rituals}

The death of a loved one often demands both a cultural and social response from the living and as such the bereaved engage in ritual repertoires, such as funerals, wakes, Janazah, and Levayah (Grimes, 2013). However, within Western society, formal religious grief rituals are often perceived as a rigid, hollow experience (Imber-Black, 
1991), where they lack meaning-making and fail to address the specific needs of individuals (Grimes, 2004). Within psychotherapy, noticeable efforts have been made to support more personal grief rituals that lead to an emotional shift (Grimes, 2013). Personal grief rituals such as lighting a candle, visiting the burial site or planting a tree can provide structure to the uncertainty of grief thus helping people to adjust (Reeves, 2011). Sas \& Coman (2016) contend that once the grief ritual is complete it is difficult to remember and reflect upon the ritual. An exception to this may be memorial tattoos as they are classified as sacred symbols (Reeves, 2011), where the ritual is inscribed in the skin and the individual displaying the tattoo becomes a lifelong memorial themselves (Bergh, 2016). Due to the symbolic action of acquiring the tattoo, the very nature of this personal ritual, and the special meaning attached (Durkheim, 1912), it has been argued that memorial tattoos become sacred for the individual (Sas \& Coman, 2016).

Recently, within Western society, there has been an increase in people utilising tattoos as a ritualistic grief medium (Cann, 2014). Tattoos are no longer such ambiguous topics associated with the disreputable and primitive (Benson, 2000), but are perceived as another form of mourning clothing (Souza \& Staudt, 2009). Cann posits that the act of tattooing is a ritual for the mourner not unlike the undertaking of seeing a therapist.

\section{Memorial Tattoos}

Tattoos as mechanisms in the grieving process have not been studied extensively, although some researchers have made reference to their use (Atkinson 2004). Some suggest that having a memorial tattoo enables us to mark our individual stories of losing a loved one in a lasting way (Wolfelt, 1997; Sarnecki, 2001), and that they can assuage grief and validate the experience of loss (Davidson \& Letherby, 2015). Davidson (2017) found that memorial tattoos have five fundamental features; permanence, as help 
adjusting to loss, communication and opening dialogue, identity change and, continuing bonds. A more detailed description of each of these five fundamental features follows.

\section{Permanence}

The death of a loved one results in a permanence of physical separation (Packman et al., 2006). Unlike the fragility of relationships and the impermanence of existence, memorial tattoos can offer constancy, stability and permanence (Baraceros, 2005). Memorial tattoos allow the living to inscribe on their body a permanent and personal physical reminder of their departed loved one (Lanigan, 2007) that will endure until the end (Fruh \& Thomas, 2012). Cann (2014) proposes that tattoo remembrances allow the dead a virtual afterlife. In a society where the bereaved are no longer given space to grieve, memorial tattoos can allow the bereaved to latently portray personal and poignant memories (Sundberg \& Kjellman, 2018) and mark upon the skin their permanent landscape of loss (Cann, 2014).

\section{As Help Adjusting to Loss}

For most individuals, the death of a loved one and the adjustment from the before to the after is a long and painful journey (Wolfelt, 2006). Transitional objects can help to ease this journey through bringing us comfort (Winnicott, 1971) and be an immeasurable aid (LaGrand, 2011). Within modern society memorial tattoos are emerging as transitional objects (Roth, 2006). They are perceived to aid the bereaved in updating their attachment representations (Arizmendi \& O'Connor, 2015), and act as a therapeutic tool which empowers the wearer to move from emotional anguish and closer towards personal improvement (Velliquette et al., 2006). The acquisition of a memorial tattoo is often perceived as a cathartic element of the memorialisation process (Lanigan, 2007). The acquisition of a memorial tattoo is often used to bring grief emotions to the surface so as to confront, experience, and heal from the pain of loss (Atkinson, 2004). The act 
of cutting into the flesh allows the pain of grief to be purged indirectly through the process of being tattooed (Cann, 2014; Atkinson, 2003). As such, they bestow ongoing emotional assistance (Cusick, 2003) where the bereaved celebrate and expand their relationship to the deceased (Nell, 2009).

\section{Communication and Opening Dialogue}

Death and grief are perceived as sensitive subjects and as such create an elephant in the room (Kettering, 2003). Grief is a natural reaction to loss, despite this, we are a griefilliterate nation (Shriver, 2014). It has been argued that it is more socially acceptable to discuss body art than talk about grief (Davidson, 2017), and as such, memorial tattoos function to engage others in the experience of loss (Davidson \& Letherby, 2015).

Although memorial tattoos are a strong form of non-verbal communication (Kress \& Van Leeuwen, 2006) they also have the ability for opening dialogue (Davidson, 2017). Kosut (2000) proposes that one of the most important and appealing characteristics of tattoos is their ability to initiate communication. Cann (2014) proposes that memorial tattoos give their wearers permission to tell their stories and discuss death and loss in a non-confrontational manner. The tattooed body tells a story (Dey \& Das, 2017) and each marked individual has a unique story to tell (Velliquette et al., 2006).

Memorial tattoos create texts that are simultaneously both confessional and personal (Oksanen \& Turtiainen, 2005). Mitchell (2007) suggests that due to their visual nature, memorial tattoos tend to be perceived as public rather than private entities. Conversely, Bergh (2016) suggests that often the bearers of memorial tattoos have a profound desire to conceal them due to their personal nature. The inscribed often choose who they share their story with (Cann, 2014). Subsequently, to a high degree, the intrinsic truth of the memorial tattoo remains with the tattooed individual (Sundberg \& Kjellman, 2018). 


\section{Continuing Bonds}

Continuing bonds theory was first developed by Klass et al., (1996) during their time studying bereaved people. As a bereavement concept, continuing bonds theory has been gaining ground (Valentine, 2008). More recently, the previous bereavement goal of emotional disengagement has been rejected (Steffen \& Coyle, 2010) as it is now accepted that the bereaved do not have to sever ties to the departed (Field et al., 2013). Neimeyer (2001) suggests that therapeutic interventions should serve to promote this inner bond as it is a normative aspect of bereavement adjustment.

Memorial tattoos are a visual illustration of the continuing bond and affirm the enduring connection of personal relationships to (Albin, 2006; Mitchell, 2007). They enable the inscribed to validate the deceased as a tangible part of themself (Davidson, 2017). and are an expressive modality which immortalises the deceased (Sundberg \& Kjellman, 2018), serving as a bank of memories (Altmaier, 2011), and aid in the ongoing relationship with the deceased (Lanigan, 2007; Cadell et al., 2020).

\section{Identity Change}

The death of a loved one is deemed as one of the most traumatic and demanding of all life's changes (Grollman, 1995). Despite this, grief has been perceived as being transformative (Balk, 1999), offering a fundamental experience for personal change and growth (Harvey, 2002).

Growth and change, following the death of a loved one is commonly associated with active acceptance strategies (Stanton et al., 2006). The acquisition of a memorial tattoo can be perceived as an active acceptance strategy as the bereaved person takes positive action, particularly in the planning of this grief ritual (Attig, 1991). Memorial tattoos have been recognised as a personal self-healing medium which is relevant to a change in identity (Altmaier, 2011). Memorial tattoos are both visual and embodied 
representations of change (Davidson, 2017) which empower the bereaved to emerge from the loss of a loved one with a 'beautiful scar' (Sweeney, 2014).

\section{Methods}

In their commentary, Davidson \& Letherby (2015) explored the experiences of individuals who have had a memorial tattoo, but the current study uses an in-depth qualitative methodology to understand the lived experiences of those who acquire such a tattoo to illuminate the grieving processes and explore whether having a memorial tattoo played a role (Larkin et al., 2008; Eatough \& Smith, 2017).

In line with this, the main purpose of this study was to address the research question: What is the lived experience of bereaved individuals having a memorial tattoo and has their memorial tattoo played a role in their grieving process?

\section{Methodological Perspective}

Grief, when created by a death, is a personal experience which is unique to each individual (Moore et al., 2013) and we wanted to acquire an understanding of how lives are lived (and lost) (Grinyer, 2002). The research, therefore, used the qualitative methodology of interpretative phenomenological analysis (IPA) which was conceptualised by Smith (1996). IPA is concerned with trying to understand lived experience; it is centrally concerned with the meanings which those experiences hold for the participants. Using this approach, coupled with a subjective and reflective process of interpretation (Chapman \& Smith, 2002), a rich and deep understanding of the grieving process and the function of memorial tattoos was achieved.

Participants were purposively identified, which consequently ensured that there would be an elevated level of participant homogeneity. Guest et al. (2006) and Mason (2010), propose that for studies with a high level of homogeneity among the participants, a sample size of six interviews is conceivably sufficient to reach saturation. 
Reid et al. (2005) suggest that when using IPA, fewer participants examined at depth is preferable to a broad, more descriptive analysis of many participants, as is commonly seen in thematic analysis or grounded theory. Smith et al. (2009) highlight that sample size is contextual and must be considered on a study-by-study basis, but as a rough guide they suggest between three and six participants are sufficient for this type of study. Once six participants had been interviewed the saturation point was determined, as many of the key themes and language were significantly consistent across the participants (Martel, 2014).

\section{Interviews}

Six individual semi-structured interviews were conducted face to face. Each participant was given the opportunity to openly share their subjective lived experience in real time (Smith, 2004; Anderson, 2010). An interview schedule was used so that each participant was able to tell their story in their own words (Smith et al., 1997) whilst also ensuring that the interviews were kept within the parameters of the research aims (Alshenqeeti, 2014). An example of some of the questions asked during the interviews include: Who did you get your memorial tattoo for? What is the symbolic meaning of your memorial tattoo? What feelings and/or thoughts do you associate with your memorial tattoo? Has your memorial tattoo been helpful/not been helpful in your grieving process?

\section{Participants}

Six participants took part; all identified as white British, five females and one male with an age range between 20 years and 45 years. Each loss was personal to the individual participant, where the nature of loss included through suicide, perinatal loss, loss of a friend and the loss of a grandparent. Purposive sampling was employed, participants were recruited from < author affiliation $>$ and from tattoo studios within the local area. All participants had a memorial tattoo. Considerable effects of bereavement can still be 
observed up to 24 months following the loss of a loved one (Prigerson \& Jacobs, 2001) and therefore we only approached those that had been bereaved for at least two years.

\section{Ethical Approval}

Ethical approval was gained from < authors affiliation>, and the British Psychological Society Code of Conduct and British Association of Counselling and Psychotherapies Ethical Frameworks were adhered to.

\section{Results and Discussion}

The themes identified in this study were similar to those identified by Davidson (2017). However, there were some differences, and as a result we have adapted Davidson's terms slightly to align more closely with our findings. The main themes identified throughout the interview transcriptions by the researcher in relation to how memorial tattoos impact upon the grieving process were 1) Permanence, 2) A tool for managing grief, 3) Communicative tool, 4) Continuing bonds, and, 5) Transformation of self. [pseudonyms are presented alongside quotes]. Photographs of the participants' memorial tattoos can be found in Appendix A.

\section{Theme 1 - Permanence}

Once a memorial tattoo is inscribed on the body it becomes a permanent mark which endures for a lifetime (Lanigan, 2007). Within this study five of the six participants discussed the importance of permanency, indicating it to be an important aspect of having a memorial tattoo.

"It will always be with me and $\uparrow$ I'll never forget him $\uparrow$ which is, I suppose $\downarrow$ the point of having the tattoo." (Gary)

"Unless I have my arm sawn off, the reminder will always be there." (Jade) 
The use of language such as "always" and "never forget" shows that there is a need for this reminder to be with them permanently, supporting Gibson (2004) that memorial objects aid the bereaved in non-forgetting.

Within the theme of permanence there was also a theme of inescapable seriousness of being permanently marked with a tattoo (Taliaferro \& Odden, 2012).

"I had to think about it a lot before choosing to have it because it is a mark that you are putting on you forever.” (Marie)

Here Marie illustrates that for many, acquisition of a tattoo requires explicit consideration in relation to its permanence (Joyce, 2005).

\section{Theme 2 - A Tool for Managing Grief}

A tool for managing grief is demonstrated heavily throughout the majority of the participants' transcripts. However, there were some differences in the impact their memorial tattoo has had in this process.

“I don’t feel like I've $\uparrow$ lost her as much anymore $\uparrow$. It's almost like she's stored

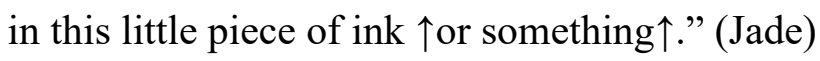

Jade refers to not having lost her friend "as much anymore" showing how her memorial tattoo has helped her in her adjustment to loss. For Jade her friend is "stored" in her ink, suggesting that her memorial tattoo is bestowing upon her deceased loved one a new existence as proposed by Sweeney (2014).

"Basically, as I had this done it was almost like an opportunity for me to open the lid $\uparrow$ off that box $\uparrow$ and help me deal with $\uparrow$ other grief $\uparrow$. Because once I'd got a perspective on what grief was it was a huge weight off me." (Angela)

The use of the linguistic device of the metaphor "lid off that box" demonstrates how Angela has kept her grief hidden inside her for a long time. Tattoos can have a variety of functions (Anderson \& Sansone, 2003); for Angela the acquisition of her memorial 
tattoo not only helped her to face her recent grief, but it also helped her to grieve for others and further helped her to actually understand what grief was.

"So:: it’s probably a $\uparrow$ physical coping mechanism as well $\uparrow$ erm through the actual procedure." (Liv)

In the extract above Liv considers the actual procedure of having her memorial tattoo as a physical coping mechanism. Sweeney (2014) proposed that the act of being tattooed enables the bereaved to translate their emotional pain into a physical pain.

“I don't think I've needed to go through the grieving process. As soon as it happened $\uparrow I$ got to the acceptance point $\uparrow$ and that was it.” (Georgie) Unusually in this group, Georgie discusses working in a care home and how for her death is a normal part of her working life. She claims that there was no need for her to adjust to the loss of her Grandad and therefore her memorial tattoo has had no function in this area of her loss.

\section{Theme 3 -Communicative Tools}

Grieving research has typically found that, individuals who are grieving want to talk about their deceased loved one (Walter, 1996). This theme was reiterated throughout the current interview in four ways: ability for opening dialogue, talking to the dead, request no reply and tactical omission.

\section{Ability for opening dialogue}

Mitchell (2007) suggests tattoos are a fundamental manner in which we communicate to others.

"Erm::, by:: having the tattoo:: it gives rise to people asking questions. I think it's a bit obvious when you have got footprints going up your back $\uparrow$ in pink and blue $\uparrow$, that it’s a loss tattoo. And people will say oh you know ' $\uparrow$ I suffered loss 
as well $\uparrow . '$ And I think it, it helps from a societal aspect to get people talking." (Angela)

Davidson (2017) stipulates that for grieving individuals shared meaning is important. Angela's choice of pink and blue baby footprints intentionally communicates that her memorial tattoo represents maternal loss which then opens up a window of opportunity in which others can share their own experience.

\section{Talking to the dead}

"And then obviously just a tool to talk to one $\uparrow$ another $\uparrow$ and even though we can't physically say I can almost hear:: her::" (Jade)

In contrast to the previous extracts, Jade discusses how her memorial tattoo is a tool through which she communicates not with the living, but with the dead. She states how she can almost hear her friend talking to her. This is in line with Marwit \& Klass (1996) who propose that an active inner representation of the deceased is a concept which naturally and readily exists to the bereaved.

Request no reply

"It communicates to me and $\downarrow$ nobody else $\downarrow . "$ (Gary)

Here Gary is clear that his tattoo is not meant to in any way open dialogue; supporting Benson (2000) who suggests that even though memorial tattoos are scars that speak, they request no reply.

\section{Tactical omission}

"I didn't do it for:: people to understand. >It was for me. If people ask me about it and I feel comfortable I will then explain the reasoning behind it." (Georgie) Georgie is selective in who she chooses to share her narrative with; she only shares her story based on the perceived reaction of the listener ((Kosut \& Moore, 2010; Cann, 2014). 


\section{Theme 4 - Continuing Bonds}

Wolfelt (2006) stipulates that anyone whom we have internalised becomes a fabric of our being and can never be truly lost, the concept of continuing bonds (Klass et al., 1996) was predominant throughout the majority of the interviews. Only one participant did not make any reference to this aspect of their memorial tattoo.

"Erm:: proximity is a $\uparrow$ big thing $\uparrow$. I guess it’s just a little bit of:: someone $\downarrow$ close to you all:: the time $\downarrow$. And even though it's not their $\uparrow$ physical body or their physical selves $\uparrow$, they're embodied in this." (Jade)

In this extract, Jade discusses the importance of proximity and utilises the phrase "embodied in this". Jade is expressing that her memorial tattoo allows her to have both a tangible and visual form of her friend. Sundberg \& Kjellman (2018) maintain that through adornments the dead are commemorated and kept physically and emotionally close.

“Although:: he isn’t, he isn't here in person that doesn’t mean $\uparrow$ he’s gone $\uparrow$.

I’ve always, he’s always:: $\uparrow$ here, and here $\uparrow$. Interviewer: You are pointing to $\uparrow$ your heart $\uparrow$ and memorial tattoo. Georgie: Yeah $\uparrow$ he’s always here $\uparrow . ”$

\section{(Georgie)}

In the above extract, Georgie is alluding to the fact that even though her Grandad is no longer alive he still lives on in her heart and in her memorial tattoo. Gibson (2004) proposes that the bereaved need a way to rehouse the life that is no longer here. Georgie's use of language "^he's always here $\uparrow$ " shows that her memorial tattoo has allowed her to do this and continue her bond with her Grandad.

\section{Theme 5 - Transformation of Self}

All participants identified at least one area of their life in which their memorial tattoo had influenced an identity change. Memorial tattoos permit their bearers to partake in 
the active process of creating their own identity, where the extended self is formulated and changed to reinvent a new personal identity (Altmaier, 2011).

“It’s erm made me a little bit more $\uparrow$ emotional $\uparrow$. Yeah, I just let myself I

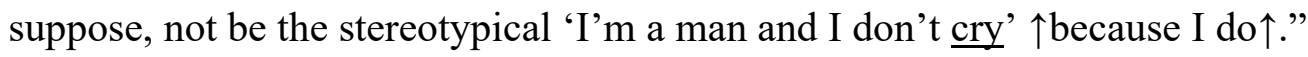
(Gary)

For Gary, his tattoo has impacted upon his emotional wellbeing as he no longer cares about being a stereotypical man. This confirms that tattoos are not always related to a diverse attitude as postulated by Frederick \& Bradley (2000).

During Angela's interview, she shared how she has struggled all her life with understanding and expressing emotions.

"It has made me $\uparrow$ grow as a person, in confidence and expression $\uparrow$, and it’s enabled me to, deal with things and not be $\uparrow$ embarrassed to talk about things that upset me. Because it is ok to cry, it is ok to be upset $\uparrow . "$ (Angela)

Ellis (2015) advocates that tattoos contribute to a personal narrative that promotes selfesteem and coherence. In this extract, Angela acknowledges how her memorial tattoo has helped her to grow as a person and in confidence. She now has a new narrative where she is able to express herself and to be more open in sharing her feelings.

\section{Conclusion}

This research supports the philosophy that grief is a complex process (Corr, 1993). The belief that normative societal grieving rituals are hollow and rigid (Imber-Black, 1991) were supported by the findings. Memorial tattoos were perceived as a more personal and meaning-making ritual (Grimes, 2013). The participants' narratives showed that their memorial tattoos served as a coping mechanism (Atkinson, 2003) in that they allowed the emotional pain of grief to be transformed into a physical pain (Sweeney, 2014). The findings further reinforce the notion that memorial tattoos offer a sense of 
stability (Baraceros, 2005), provide ongoing emotional support (Cusick, 2003), and act as a permanent reminder of the deceased (Cann, 2014). As transitional objects memorial tattoos were perceived to be an immeasurable aid (LaGrand, 2011) in helping the participants adjust to their loss (Winnicott, 1971). They were also found to serve the bereaved in their attachment representations (Arizmendi \& O'Connor, 2015), bring grief emotions to the surface (Atkinson, 2004), and validate and honour their relationship to the deceased (Nell, 2009).

There was diversity in the findings relating to memorial tattoos as communicative tools. Although memorial tattoos can initiate communication (Kosut, 2000), and engage others in the experience of loss (Davidson \& Letherby, 2015), they are not always perceived by the individuals as public entities (Mitchell, 2007). Memorial tattoos can be very personal (Bergh, 2016), and although they are scars that speak (Benson, 2000), some individuals chose to employ tactical omission (Kosut \& Moore, 2010) to ensure that their tattoo's inherent truth remained with them (Sundberg \& Kjellman, 2018). This study further supports the theory of continuing bonds, as none of the participants felt they had severed their ties to the deceased (Field et al., 2013). The participants shared how their memorial tattoos helped them to affirm their connection to the deceased (Albin, 2006), act as a daily reminder of their loved one (Lanigan, 2007) and bequeath upon the deceased a new existence (Sweeney, 2014). The concept that memorial tattoos can aid the personal growth and change of the bereaved (Harvey, 2002) was supported in this study. The participants shared their stories of how their memorial tattoos acted as a personal self-healing medium (Altmaier, 2011), and have promoted their self-esteem (Ellis, 2015).

This study has shown that memorial tattoos can enable individuals to mark their stories of grief (Sarnecki, 2001), and play varying fundamental roles within the grieving 
process (Davidson, 2017). The acquisition of memorial tattoos should therefore be considered an important grieving ritual (Imber-Black, 1991) as they are often utilised by the bereaved as a therapeutic tool (Velliquette et al., 2006). Western societal perspectives of tattoos and, in particular, memorial tattoos as a deviant representation, need to be challenged. Memorial tattoos are a unique artistic form in which the bereaved can express and memorialise their contemporary, lived experience (Davidson, 2017).

Individuals who have been etched with a memorial tattoo offer a very unique and enlightening perspective on the grieving process. It is only through hearing their stories of memorialisation that we will be able to inform, challenge, and shape our future understanding of memorial tattoos as expressions of grief.

\section{Acknowledgements}

First and foremost, I (Bee) owe a debt of gratitude to my Dad whose departing from this earth touched deep within my soul and inspired this research. Thank you for instilling within me the determination to achieve my goals and for helping me to believe that I can achieve anything I put my mind to. A special thank you to all my participants, without your willingness to participate none of this would have been possible. It has been an honour to share in your memorial stories. You have all touched my heart.

\section{Declaration of Interest}

There are no relevant financial or non-financial competing interests to report.

\section{References}

Albin, D. D. (2006). Making the body (w)hole: A semiotic exploration of body modifications. Psychodynamic practice, 12(1), 19-35. https://doi.org/10.1080/14753630500471960

Alshenqeeti, H. (2014). Interviewing as a data collection method: A critical review. English Linguistics Research, 3(1), 39-45. https://doi.org/10.5430/elr.v3n1p39

Altmaier, E. M. (2011). Best practices in counseling grief and loss: Finding benefit from trauma. Journal of Mental Health Counseling, 33(1), 33-45. https://doi.org/10.17744/mehc.33.1.tu9wx5w3t2145122 
Anderson, C. (2010). Presenting and evaluating qualitative research. American Journal of Pharmaceutical Education, 74(8), 1-7. https://doi.org/10.5688/aj7408141

Anderson, M., \& Sansone, R. A. (2003). Tattooing as a means of acute affect regulation. Clinical Psychology and Psychotherapy, 10(5), 316-318. https://doi.org/10.1002/cpp.374

Arizmendi, B. F., \& O'Connor, M. F. (2015). What is "normal" in grief? Australian Critical Care, 28(2), 58-62. https://doi.org/10.1016/j.aucc.2015.01.005

Atkinson, M. (2004). Tattooing and civilizing processes. Body modifications as selfcontrol. Canadian Review of Sociology and Anthropology, 42(1), 1-31. https://doi.org/10.1111/j.1755-618X.2004.tb02173.x

Atkinson, M. (2003). Tattooed: The sociogenesis of a body art. University of Toronto Press.

Attig, T. (1991). The importance of conceiving of grief as an active process. Death Studies, 15(4), 385-394. https://doi.org/10.1080/07481189108252443

Balk, D. E. (1999). Bereavement and spiritual change. Death Studies, 23(6), 485-494. https://doi.org/10.1080/074811899200849

Baraceros, E. L. (2005). Communication skills 1: Improving study and thinking skills. Rex Book Store, Inc.

Benson, S. (2000). Inscriptions of the self: Reflections on tattooing and piercing in contemporary Euro-America. In J. Caplan (Ed.) Written on the body: The tattoo in European and American history (pp. 234-254). Reaktion Books Ltd

Bergh, L. (2016). Tattooing as memorial pragmemes. In K. Allan, A. Capone \& I. Kecskes (Eds.) Pragmemes and theories of language use (pp. 585-600). Springer International Publishing

Bonanno, G. A., \& Kaltman, S. (1999). Toward an integrative perspective on bereavement. Psychological Bulletin, 125(6), 760-776. https://doi.org/10.1037/00332909.125.6.760

Bowlby, J. (1979). The making and breaking of affectional bonds. Tavistock

Boyraz, G., Horne, S. G., \& Waits, J. B. (2015). Accepting death as part of life: Meaning in life as a means for dealing with loss among bereaved individuals. Death Studies, 39(1), 1-11. https://doi.org/10.1080/07481187.2013.878767

Cadell, S., Lambert, M. R., Davidson, D., Greco, C., \& Macdonald, M. E. (2020). Memorial tattoos: Advancing continuing bonds theory. Death Studies, 44(12), 1-8. https://doi.org/10.1080/07481187.2020.1716888

Cann, C. K. (2014). Virtual afterlives: Grieving the dead in the twenty-first century. University Press of Kentucky

Chapman, E., \& Smith, J. A. (2002). Interpretative phenomenological analysis and the new genetics. Journal of Health Psychology, 7(2), 125-130. https://doi.org/10.1177/1359105302007002397

Corr, C. A. (1993). Coping with dying: Lessons that we should and should not learn from the work of Elisabeth Kübler-Ross. Death Studies, 17(1), 69-83. https://doi.org/10.1080/07481189308252605

Cusick, J. (2003). Spirituality and voluntary pain. American Pain Society Bulletin 13(5), 1-5. https://doi.org/10.1080/02682621.2017.1305055 
Davidson, D. (2017). Art embodied: Tattoos as memorials. Bereavement Care, 36(1), 33-40. https://doi.org/10.1080/02682621.2017.1305055

Davidson, D., \& Letherby, G. (2015). Editorial introduction special edition: Loss, bereavement, and creativity. Illness, Crisis \& Loss, 23(4), 298-290. https://doi.org/10.1177/1054137315590738

Davis, C. G., Wortman, C. B., Lehman, D. R., \& Silver, R. C. (2000). Searching for meaning in loss: Are clinical assumptions correct? Death Studies, 24(6), 497-540. https://doi.org/10.1080/07481180050121471

Dey, A., \& Das, K. (2017). Why we tattoo? Exploring the motivation and meaning. Anthropology 5(1), 174-179. https://doi.org/10.4172/2332-0915.1000174

Durkheim, E. (1912). The elementary forms of the religious life. Free Press

Eatough, V., \& Smith, J. A. (2017). Interpretative phenomenological analysis. In C. Willig \& W. Stainton-Rogers (Eds.) The SAGE handbook of qualitative research psychology (2 ${ }^{\text {nd }}$ ed., pp. 193-210). SAGE Publications Ltd

Ellis, A. D. (2015). A picture is worth one thousand words: Body art in the workplace. Employee Responsibilities and Rights Journal, 27(2), 101-113. https://doi.org/10.1007/s10672-014-9254-1

Field, N. P., Packman, W., Ronen, R., Pries, A., Davies, B., \& Kramer, R. (2013). Type of continuing bonds expression and it's comforting versus distressing nature: Implications for adjustment among bereaved mothers. Death Studies 37(10), 889912. https://doi.org/10.1080/07481187.2012.692458

Frederick, C., \& Bradley, K. (2000). A different kind of normal? Psychological and motivational characteristics of young adult tattooers and body piercers. North American Journal of Psychology, 2(2), 379-392. https://www.researchgate.net/publication/283986151

Freud, S. (1917). Mourning and melancholia. The standard edition of the complete psychological works of Sigmund Freud, Volume XIV (1914-1916): On the history of the psycho-analytic movement, papers on metapsychology and other works, 237-258. Basic Books

Fruh, K., \& Thomas, E. (2012). Tattoo you: Personal identity in ink. In R. Arp (Ed.) Tattoos - Philosophy for everyone: I ink, therefore I am (pp. 83-95). John Wiley \& Sons, Inc.

Gibson, M. (2004). Melancholy objects. Mortality, 9(4), 285-299. https://doi.org/10.1080/13576270412331329812

Grimes, R. L. (2013). Beginnings in ritual studies ( $3^{\text {rd }}$ ed.). Ritual Studies International

Grimes, R. L. (2004). Consuming ritual: A \& E's sacred rites and rituals. In C. Otnes \& T. Lowrey (Eds.) Contemporary consumption rituals: A research anthology (pp. 2136). Lawrence Erlbaum

Grinyer, A. (2002). Cancer in young adults: Through parent's eyes. Open University Press

Grollman, E. A. (1995). Living when a loved one has died (3 ${ }^{\text {rd }}$ ed.). Beacon Press

Guest, G., Bunce, A., \& Johnson, L. (2006). How many interviews are enough? An experiment with data saturation and variability. Field Methods, 18(1), 59-82. https://doi.org/10.1177/1525822X05279903 
Harvey, J. (2002). Perspective on loss and trauma: Assaults on the self. Sage Publications, Inc.

Imber-Black, E. (1991). Rituals and the healing process. In F. Walsh \& M. McGoldrick (Eds.) Living beyond loss: Death in the family (pp. 207-223). W. W. Norton \& Company, Inc.

Joyce, R. A. (2005). Archaeology of the body. Annual Review of Anthropology, 34(1), 139-158. https://doi.org/10.1146/annurev.anthro.33.070203.143729

Kettering, T. (2003). The elephant in the room. In S. L. Latta \& M. Rosen (Eds.) Dealing with the loss of a loved one (pp. 50-51). Chelsea House Publishers

Klass, D., Silverman, P. R., \& Nickman, S. L. (1996). Continuing bonds: New understandings of grief. Taylor \& Francis

Kosut, M. (2000). Tattoo narratives: The intersection of the body, self-identity and society. Visual Studies, 15(1), 79-100. https://doi.org/10.1080/14725860008583817

Kosut, M., \& Moore, L. J. (2010). Introduction: Not just the reflexive reflex. Flesh and bone in the social sciences. In L. J. Moore \& M. Kosut (Eds.) The body reader: Essential social and cultural readings (pp. 1-30). New York University Press

Kress, G., \& Van Leeuwen, T. (2006). Reading images: The grammar of visual design ( $2^{\text {nd }}$ ed.). Routledge

Kübler-Ross, E. (1969). On death and dying. The Macmillan Company

LaGrand, L. E. (2011). Healing grief, finding peace: 101 ways to cope with the death of your loved one. Sourcebooks, Inc.

Lanigan, K. (2007). Memorial in ink. Veterans of Foreign War Magazine, 95(3), 42-43.

Larkin, L., Watts, S., \& Clifton, E. (2008). Giving voice and making sense in interpretative phenomenological analysis. Qualitative Research in Psychology, 3(2), 102-120. https://doi.org/10.1191/1478088706qp062oa

Leming, M. R., \& Dickinson, G. E. (2020). Understanding dying, death and bereavement ( $9^{\text {th }}$ ed.). Cengage Learning, Inc.

Lindemann, E. (1944). Symptomatology and management of acute grief. The American Journal of Psychiatry, 101(2), 141-148. https://doi.org/10.1176/ajp.101.2.141

Martel, S. L. (2014). Picturing life-stories in a biomedical setting: A phenomenological analysis of neonatal end-of-life photography. (Unpublished Doctoral Thesis: York University, Canada)

Marwit, S. J., \& Klass, D. (1996). Grief and the role of the inner representation of the deceased. In D. Klass, P. R. Silverman \& S. L. Nickman (Eds.) Continuing bonds: New understandings of grief (pp. 297-308). Taylor \& Francis

Mason, M. (2010). Sample size and saturation in PhD studies using qualitative interviews. Forum: Qualitative Social Research, 11(3), Art.8. https://doi.org/10.17169/fqs-11.3.1428

Mitchell, M. (2007). Constructing immortality: The role of the dead in everyday life. In M. Mitchell (Ed.) Remember me, constructing immortality: Beliefs on immortality, life, and death (pp. 1-18). Routledge

Moore, T., Parrish, H., \& Black, B. P. (2013). Interconception care for couples after perinatal loss: A comprehensive review of the literature. Journal of Perinatal and Neonatal Nursing, 25(1), 44-51. https://doi.org/10.1097/JPN.0b013e3182071a08 
Morris, S. (2008). Overcoming grief: A self-help guide using cognitive behavioral techniques. Robinson

Neimeyer, R. A. (2001). Reauthoring life narratives: Grief therapy as meaning reconstruction. Israel Journal of Psychiatry and Related Sciences, 38(3-4), 171-183.

Nell, W. (2009). The saying hallo metaphor as alternative approach to death-related counselling. In A. Kosher (Ed.) Dying, assisted death and mourning (pp. 117-134). Rodopi

Nolen-Hoeksema, S., \& Larson, J. M. (1999). Coping with loss. Lawrence Erlbaum Associates

Oksanen, A., \& Turtiainen, J. (2005). A life told in ink: Tattoo narratives and the problem of the self in late modern society. Auto/Biography, 13(2), 111-130. https://doi.org/10.1191/0967550705ab021oa

Packman, W., Horsley, H., Davies, B., \& Kramer, R. (2006). Sibling bereavement and continuing bonds. Death Studies, 30(9), 817-841. https://doi.org/10.1080/07481180600886603

Prigerson, H. G., \& Jacobs, S. C. (2001). Traumatic grief as a distinct disorder: A rationale, consensus criteria, and a preliminary empirical test. In M. S. Stroebe, R. O. Hansson, W. Stroebe \& H. Schut (Eds.) Handbook of bereavement research (pp. 613-645). American Psychological Association

Reeves, N. C. (2011). Death acceptance through ritual. Death studies, 35(5), 408-419. https://doi.org/10.1080/07481187.2011.552056

Reid, K., Flowers, P., \& Larkin, M. (2005). Exploring the lived experience. The Psychologist, 18(1), 20-23. https://thepsychologist.bps.org.uk/volume-18/edition1/exploring-lived-experience

Robben, A. C. G. M. (2004). Death and anthropology: An introduction. In A. C. G. M. Robben (Ed.), Death, mourning and burial: A cross-cultural reader (pp.1-16). Blackwell Publishing

Roth, D. (2006). Adornment as a method of interior design. Studies in Gender and Sexuality, 7(2), 179-194.

https://www.tandfonline.com/doi/abs/10.2513/s15240657sgs0702_4?journalCode=hs gs20

Sarnecki, J. (2001). Trauma and tattoo. Anthropology of Consciousness, 12(2), 35-42. https://doi.org/10.1525/ac.2001.12.2.35

Sas, C., \& Coman, A. (2016). Designing personal grief rituals: An analysis of symbolic objects and actions. Death Studies, 40(9), 558-569. https://doi.org/10.1080/07481187.2016.1188868

Shriver, M. (2014). Foreword to the anniversary edition. In E. Kübler-Ross \& D. Kessler (Eds.) On grief and grieving: Finding the meaning of grief through the five stages (pp.xi-xiv). Scribner

Smith, J. A. (2004). Reflecting on the development of interpretative phenomenological analysis and its contribution to qualitative research in psychology. Qualitative Research in Psychology, 1(1), 39-54. https://doi.org/10.1080/08870449608400256 
Smith, J. A. (1996). Beyond the divide between cognition and discourse. Psychology \& Health, 11(2), 261-271. https://www.tandfonline.com/doi/abs/10.1191/1478088704qp004oa

Smith, J. A., Flowers, P., \& Larkin, M. (2009). Interpretative phenomenological analysis: Theory, method and research. SAGE Publications Ltd

Smith, J. A., Flowers, P., \& Osborn, M. (1997). Interpretative phenomenological analysis and the psychology of health and illness. In L. Yardley (Ed.) Material discourses of health and illness (pp. 68-91). Routledge

Souza, M., \& Staudt, C. (2009). The many ways we talk about death in contemporary society: Interdisciplinary studies in portrayal and classification. Edwin Mellen Press Ltd

Steffen, E. M., \& Coyle, A. (2010). Can 'sense of presence' experiences in bereavement be conceptualized as spiritual phenomena? Mental Health, Religion and Culture 13(3), 273-91. https://doi.org/10.1080/13674670903357844

Sundberg, K., \& Kjellman, U. (2018). The tattoo as a document. Journal of Documentation, 74(1), 18-35. https://doi.org/10.1108/JD-03-2017-0043

Stanton, A. L., Bower, J. E., \& Low, C. A. (2006). Posttraumatic growth after cancer. In L. G. Calhoun \& R. G. Tedeschi (Eds.) Handbook of posttraumatic growth (pp. 138175). Erlbaum

Sweeney, K. (2014). American afterlife: Encounters in the custom of mourning. The University of Georgia Press

Taliaferro, C., \& Odden, M. (2012). Tattoos and the tattooing arts in perspective: An overview and some preliminary observations. In R. Arp (Ed.) Tattoos, philosophy for everyone: I ink, therefore I am (pp. 3-13). John Wiley \& Sons

Valentine, C. (2008). Bereavement narratives: Continuing bonds in the twenty-first century. Routledge

Velliquette, A. M., Murray, J. B., \& Evers, D. J. (2006). Inscribing the personal myth: The role of tattoos in identification. Research in Consumer Behavior 10, 35-70. https://doi.org/10.1016/S0885-2111\%2806\%2910003-4

Wakefield, J. C. (2013). Is complicated/prolonged grief a disorder? Why the proposal to add a category of complicated grief disorder to the DSM- 5 is conceptually and empirically unsound. In M. Stroebe, H. Schut \& J. Van Den Bout (Eds.), Complicated grief: Scientific foundations for health care professionals (pp.99-114). Routledge

Walter, T. (1996). A new model of grief: Bereavement and biography. Mortality, 1(1), 7-25. https://doi.org/10.1080/713685822

Winnicott, D. W. (1971). Playing and reality. Tavistock Publications Ltd

Wolfelt, A. D. (2006). The journey through grief: Reflections on healing (2 $2^{\text {nd }}$ ed.). Companion Press

Wolfelt, A. D. (1997). The journey through grief: Reflections on healing. Companion Press

Worden, J. W. (1991). Grief counseling and grief therapy: A handbook for the mental health practitioner. Routledge 


\section{Appendix 1}

Figure 1. Marie's "Stars" tattoo in memory of her uncle.

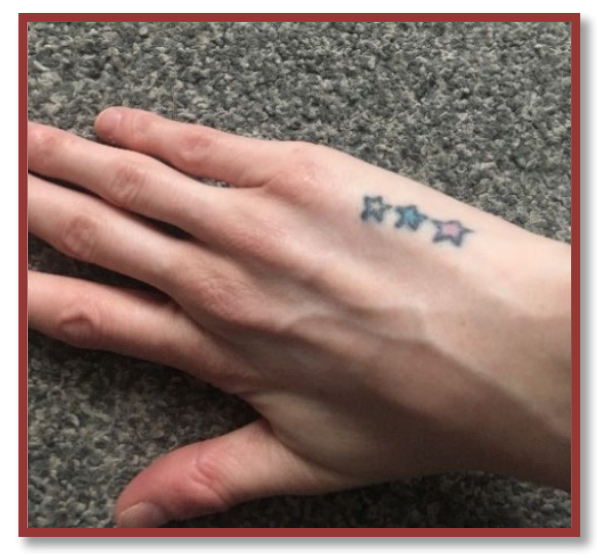

Figure 2. Liv's memorial tattoo for her friend Ed who committed suicide.

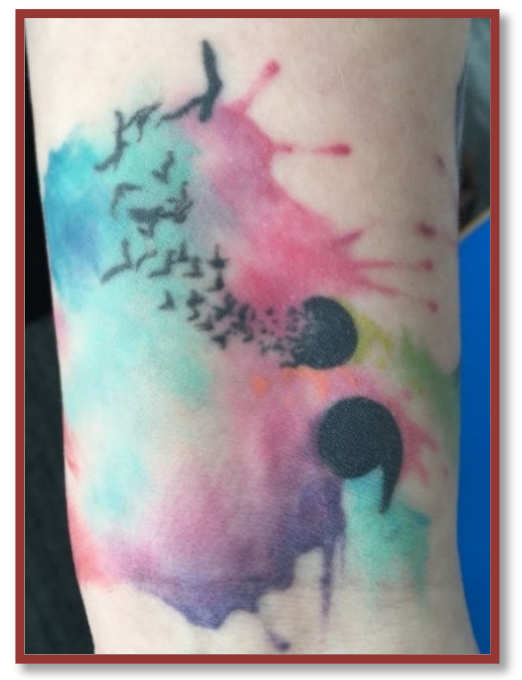

Figure 3. Angela's memorial tattoo in memory of her unborn babies.

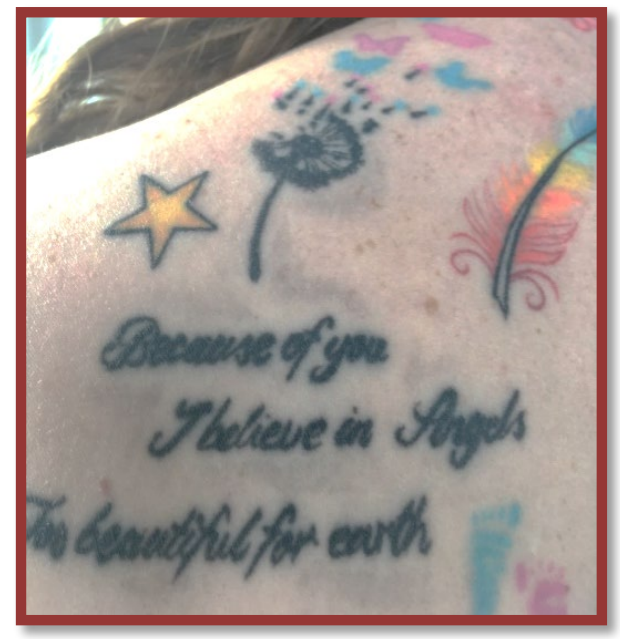


Figure 4. Jade's memorial tattoo in memory of her best friend who committed suicide at the age of 14 .

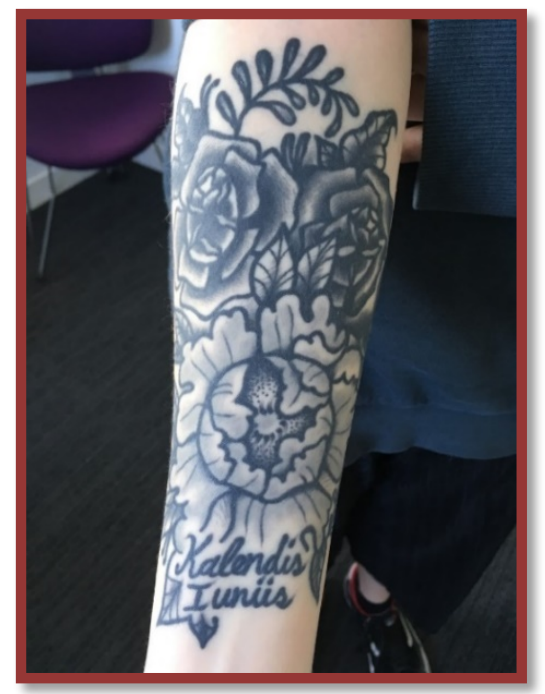

Figure 5. Georgie's memorial tattoo of her Gramps' favourite bird.

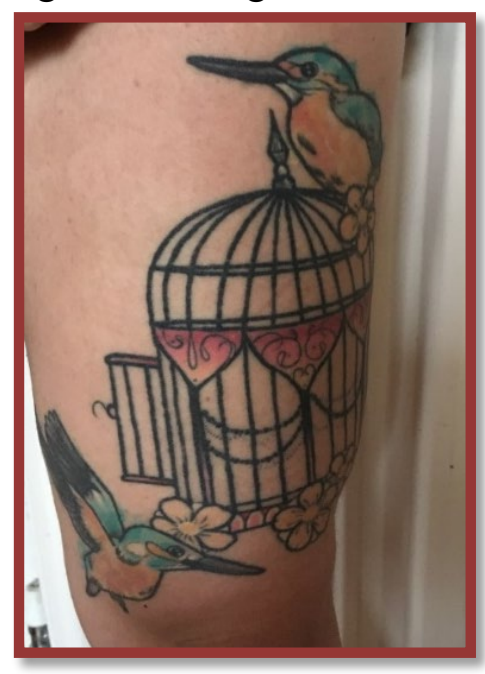

Figure 6. Gary's "On a mission" tattoo for his friend John, hidden within his previous tattoo.

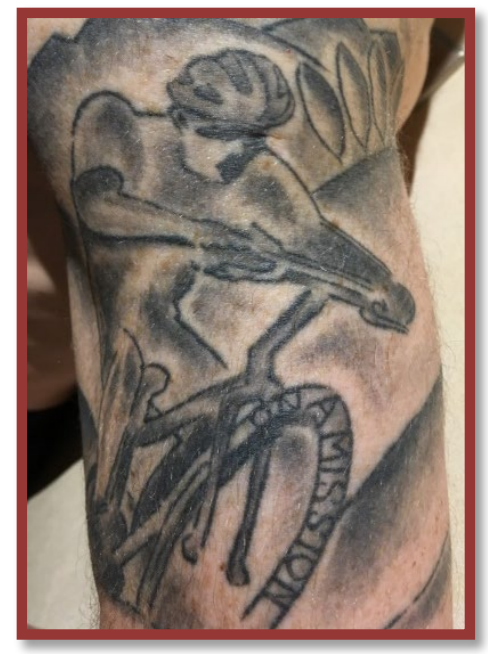


